\title{
Tune or Text? Tune-text accommodation strategies in Portuguese
}

\author{
Sónia Frota, Marisa Cruz , Joelma Castelo , Nádia Barros , Verònica Crespo-Sendra , \\ Marina Vigário \\ Center of Linguistics, University of Lisbon, Portugal \\ sonia.frota@mail.telepac.pt, marisasousacruz@gmail.com, joelmacastelo@gmail.com, \\ nadia.barros@campus.ul.pt, vcs.grep@gmail.com, marina.vigario@mail.telepac.pt
}

\begin{abstract}
In Portuguese, different strategies for dealing with tune-text accommodation have been reported. However, no systematic research has been conducted exploring crucial cases of complex nuclear melodies realized in nuclear words with final stress, as in yes-no questions. Based on reading and semispontaneous data from ten regions in Brazil and eleven regions in Portugal, this study reveals that Brazilian and European Portuguese globally differ with respect to the strategies implemented: in Brazilian Portuguese, the text is preserved and the melody is changed (mostly by means of tonal truncation); in European Portuguese, the melody is preserved and the text is changed through various strategies, including schwa epenthesis. Faithfulness to the text or to the tune is thus a relevant dimension of variation both across and within languages, and text changes (through vowel lengthening, vowel split, vowel epenthesis, or blocking of vowel deletion) are crucial means to support tune realization that have recently been found in unrelated languages.
\end{abstract}

Index Terms: tune-text association, truncation, epenthesis, prosodic variation, Portuguese, yes-no questions, statements

\section{Introduction}

In the autosegmental-metrical model of intonational phonology, intonation consists of a string of tones (the tune) that associates with elements in the segmental string, such as syllables or phrase edges (the text). The ways in which the tune and the text are related have been found to differ across languages [1], [2], as well as within languages [3]. The crucial cases are those where the text is too short for bearing the tune, as in complex tunes realized in monosyllabic phrases or in a nuclear word with final stress. In such cases the tune can be accommodated to fit the text, either by tune compression or tune truncation. Another possibility is to adjust the text to fit the tune, namely by extending the segmental material. The present paper is concerned with tune-text accommodation strategies across European and Brazilian varieties of Portuguese.

In Brazilian Portuguese (BP), both compression and truncation have been reported for the Rio de Janeiro variety on the basis of yes-no questions and requests, which typically show a rising-falling contour (LHL) [4], [5]. This variety of BP seems to favor tune adjustments, being thus similar to English - generally described as a compression language [1], and to Palermo Italian or Friulian that have been described as truncation languages [6], [7]. However, to our knowledge, no systematic research has been conducted focusing on tune-text accommodation in BP
In European Portuguese (EP), adjustments of the text have been reported for the Lisbon variety [8], [9]. The yes-no question contour is characterized by a falling-rising nuclear melody $\left(\mathrm{H}+\mathrm{L}^{*} \mathrm{LH} \%\right)$. If the phrase-final word is stress-final, one of two kinds of text adjustment emerges: (i) lengthening of the stressed vowel (leading to the perception of two vowels or vowel split); (ii) vowel epenthesis (through the insertion of a final schwa [i]). If the phrase-final word has penult stress and ends with a schwa vowel (as in ponte ['põti] 'bridge'), regular deletion of word-final schwa [10] is blocked. Importantly, none of these text adjustments obtains in neutral statements, which are characterized by a falling contour $(\mathrm{H}+\mathrm{L} * \mathrm{~L} \%)$. This tendency towards text accommodation to the tune was also reported for three other varieties of EP [11]. Recent studies on different languages like Bari Italian [12] and Tashlhiyt Tamazight (Berber) [13] have described the presence of epenthetic schwa driven by the realization of complex melodies, similarly to findings for EP.

The difference in tune-text accommodation strategies in BP and EP seems striking, but previous studies were restricted to a few varieties only and to limited data sets. To explore tune-text accommodation in Portuguese we used the speech database from the Interactive Atlas of the Prosody of Portuguese. Both reading and semi-spontaneous speech were considered from ten regions in Brazil and eleven regions in Portugal. We selected utterances that end in words with final stress, which bear a falling-rising or rising-falling tune. Across Portuguese varieties, complex tunes appear mostly in yes-no questions. Thus, we focused on this sentence type and compared yes-no questions to statements, which always show a falling/low tune in Portuguese. In the case of EP, data with nuclear words with a final schwa vowel was also considered, to investigate tune driven blocking of vowel deletion. A systematic comparison between BP and EP, on the one hand, and among varieties of $\mathrm{BP}$ and varieties of $\mathrm{EP}$, on the other hand, using the same segmental materials and sentence types, will show to what extent faithfulness to the tune or faithfulness to the text is a relevant dimension of variation in Portuguese, contributing to our understanding of tune-text accommodation strategies across and within languages.

\section{Method}

\subsection{Speech materials}

Speech materials from the Interactive Atlas of the Prosody of Portuguese (InAPoP) database were used. These materials were collected using a reading task and a discourse completion task (DCT). For each of these tasks, a Brazilian and a European Portuguese version were designed, which are available at the InAPoP website (http://labfon.letras.ulisboa.pt/ 
InAPoP/). Utterances were considered from ten regions in Brazil along the Atlantic coast - Paraíba, Pernambuco, Sergipe, Bahia, Minas Gerais, Rio de Janeiro, São Paulo, Paraná, Santa Catarina and Rio Grande do Sul - and eleven regions in Portugal, including the islands of Madeira and Azores - Bragança, Braga, Porto, Coimbra, Castelo Branco, Lisboa, Évora, Beja, Faro, Funchal (Madeira) and Ponta Delgada (Azores). From this data set, only yes-no questions and statements that end in words with final stress were selected. For EP, nuclear words with penult stress that end with a schwa vowel were also considered.

The intonation of statements and yes-no questions was previously studied and thus the typical contours of these utterances for each region, when the text does not impose constraints on tune realization, have been independently established [8], [11], [14], [15], [16]. Examples of the complex tunes that characterize yes-no questions, in contrast with the simple fall found in neutral statements, are given in Figure 1 (capitals signal word stress). In total, 2876 yes-no questions (1248 for BP and 1628 for EP) and 998 statements (492 for BP and 506 for EP) were analysed.
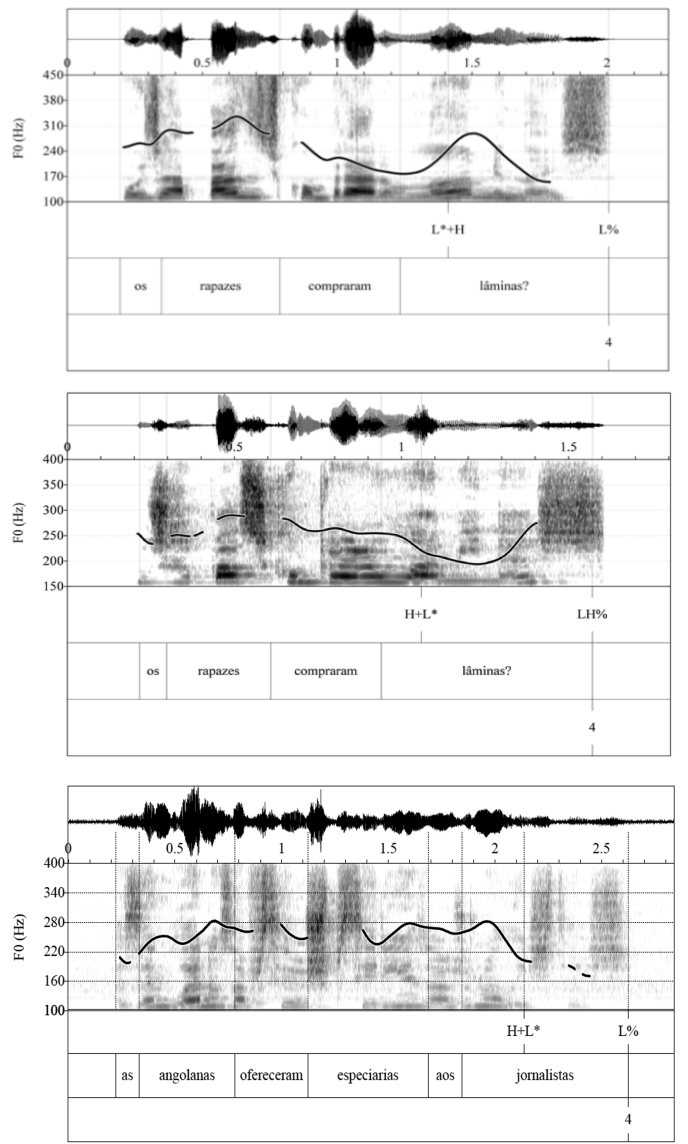

Figure 1: Representative contours of yes-no questions in BP (Rio de Janeiro - top), EP (Lisbon - mid), and neutral statements (Lisbon - bottom). Nuclear words: LÂminas 'slides'; jornaLIStas 'journalists'.

\subsection{Participants and data collection procedure}

The InAPoP database comprises data from three female speakers (aged 20-45) with high school or college education, for each region.
Data collection took place in loco with participants seated in front of a computer screen wearing a headset microphone (DPA d:fine, $20 \mathrm{~Hz}-20 \mathrm{KHz}$ ). Different recording equipment was used depending on the resources available in a given region. Each utterance was presented individually with its context. Participants were instructed to read silently the context and the utterance, and then to produce the later aloud as naturally as possible. In the case of the DCT, participants interacted with an interviewer. At least two natural/fluent renditions of each utterance were obtained per participant.

\subsection{Analysis}

Utterances were segmented and annotated with Praat [17]. Three main tiers were created: tonal, orthographic, and phrasing tiers. Tune adjustments were annotated in the tonal tier, and text adjustments were annotated in the orthographic tier, following the annotation conventions of P-ToBI [18]. An example is given in Figure 2, which illustrates a case of vowel epenthesis (from EP - Lisbon).

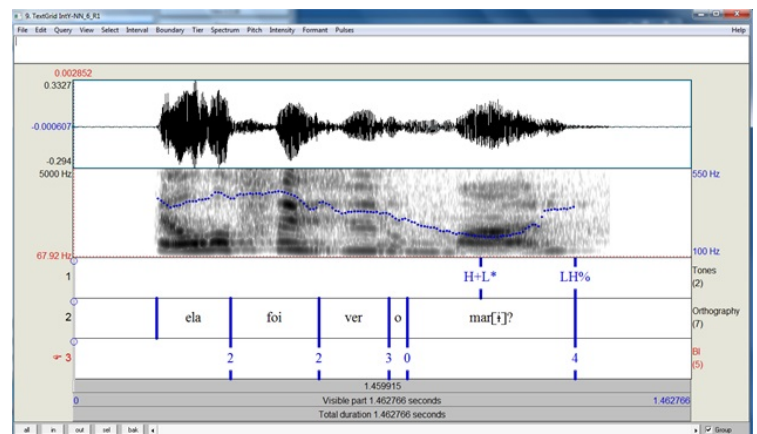

Figure 2: Example of segmentation and annotation.

The labeling of tune and text adjustments was based on perceptual and acoustic analysis carried out by one researcher and checked by a second researcher. The following phenomena were considered: (i) truncation, defined as the non-full realization of a tone (undershooting was labeled as truncation); (ii) vowel lengthening, as a perceptively clear elongation in comparison with the statement counterpart; (iii) vowel split, as the perception of two vowels instead of one

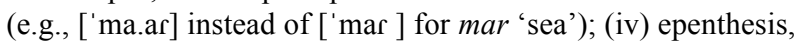
i.e., vowel insertion that typically occurs in nuclear words ending in syllables closed by a sonorant (e.g., ['ma.ri] instead of ['mar]; (v) blocking of word-final schwa deletion, as in nove 'nine', a word with penult stress (specific of EP). Compression was not considered, as it would imply a detailed analysis of tonal alignment, together with materials where the pre-nuclear stretch was controlled in number of syllables and presence/absence of pitch accents. The InAPoP materials were not designed for this purpose.

A quantitative descriptive analysis was made by region, and the percentage of occurrence of each type of adjustment was computed. These percentages were the input data for geographical models of prosodic variation, such as the Inverse Distance Weight (IDW) model, based on the degree of similarity between regions, and the Huff model which generates probabilities based on the attraction power of each geographical point studied [19]. Differently from traditional approaches commonly used to represent geolinguistic variation, these geographical models are innovative in the sense that they not only capture patterns of variation for a given set of studied locations, but also predict patterns of 
spatial interpolation or interaction for unstudied points, using deterministic and stochastic techniques. Furthermore, these methods are known to be robust (yielding low root-squaredmean errors), as long as the input dataset is large enough.

\section{Results and Discussion}

\subsection{Neutral Statements}

The intonation contours of neutral statements showed the expected falling melody $\left(\mathrm{H}+\mathrm{L}^{*} \mathrm{~L} \%\right)$ that characterizes this type of utterance in all varieties of BP and the falling or low contour $\left(\mathrm{H}+\mathrm{L}^{*} \mathrm{~L} \%\right.$ or $\left.\mathrm{L}^{*} \mathrm{~L} \%\right)$ found in varieties of $\mathrm{EP}$. No instances of tune accommodation to the text were found.

Similarly, the text was preserved across varieties of Portuguese, that is, no text adjustments were found. We noted only two regional phenomena that had been previously described in the literature [20], [21], and which occur independently of the intonation contour and/or the length of the segmental material: in BP, lengthening of the nuclear syllable in Rio de Janeiro (with 21\%); in EP, final vowel epenthesis in Beja (with 4\%).

These findings are captured in Figures 3 and 4.

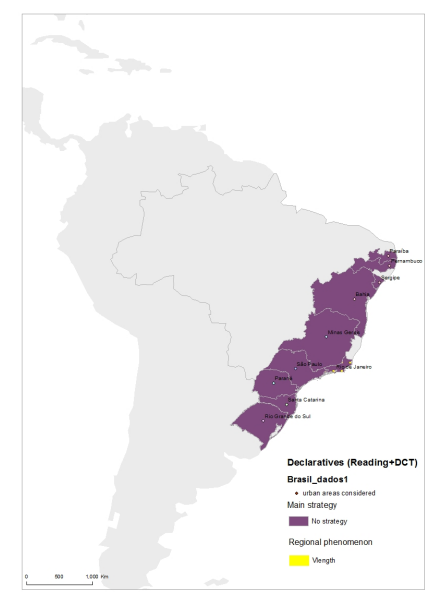

Figure 3: BP. Absence of tune-text accommodation in neutral statements (No strategy). Huff model.

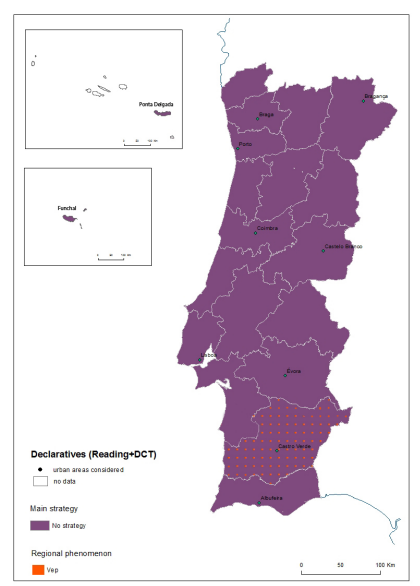

Figure 4: EP. Absence of tune-text accommodation in neutral statements (No strategy). Huff model.
By and large, the simple falling/low tune does not trigger tunetext accommodation in Portuguese.

\subsection{Yes-no questions}

Previous work on the intonation of yes-no question in BP had shown that the complex rising-falling contour $\left(\mathrm{L}^{*}+\mathrm{H} \mathrm{L} \%\right.$ or $\mathrm{L}^{*} \mathrm{HL} \%$ ) is a feature of Center and Southern varieties, whereas in Northern varieties a rising contour is predominant [15], [16]. We thus focused the analysis of tune-text accommodation in the regions with the complex tune (shown in Fig. 1), namely Minas Gerais, Rio de Janeiro, São Paulo, Paraná, Santa Catarina and Rio Grande do Sul. In all these regions, truncation of $\mathrm{L} \%$ is the dominant strategy of accommodation (overall mean frequency of $84 \%$ ). Figure 5 illustrates a case of truncation. Vowel lengthening may occasionally occur, usually together with earlier alignment of the rising contour to accommodate the following fall. No other kind of adjustment was found in the BP data.

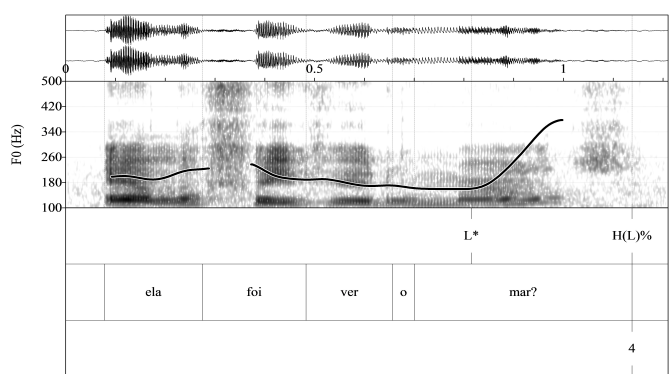

Figure 5: Representative contour of yes-no questions in BP (Rio Grande do Sul), showing truncation of L\%.

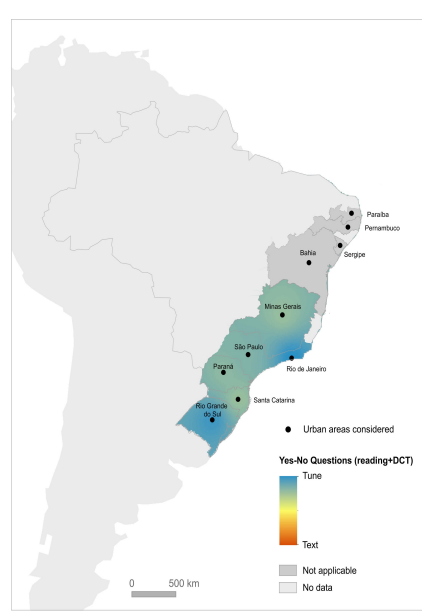

Figure 6: Tune-text accommodation in yes-no questions in BP: mapping prosodic variation using the IDW model.

Figure 6 shows the patterns of prosodic variation in tunetext accommodation in $\mathrm{BP}$ on the basis of the IDW geographical model of analysis. It is clear that in BP adjustments of the tune (truncation) are preferred to adjustments of the text.

In EP, previous studies have reported a variety of contours for yes-no questions, and all regions may show complex tunes to the exception of Faro and Ponta Delgada [11], [15]. Again, focusing on the regions with complex tunes, we found a 
diversity of tune-text accommodation strategies: in the North, truncation prevails (mean 58\%); in the Center, which appears as a transition region, both tune and text adjustments co-occur (Figure 7); in Lisbon, in the South and in Funchal (Madeira), only text adjustments were found (mean 90\%). Among these, blocking of final schwa deletion (Figure 8) is especially frequent in Lisbon, the South and Funchal (66\%), epenthesis is a relevant strategy in the center-southern interior regions and Lisbon (17\%), and vowel split occurs mostly in Lisbon and Funchal (21\%).

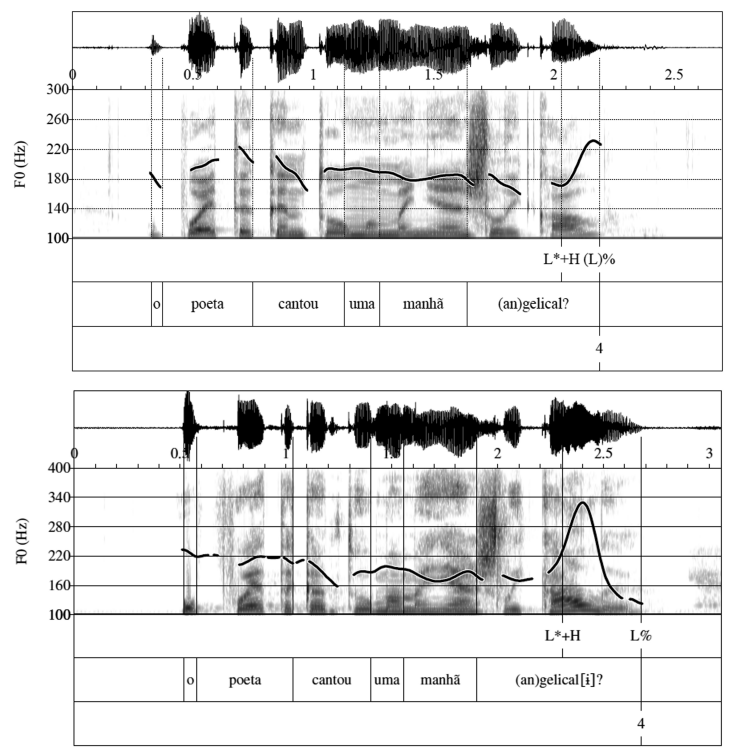

Figure 7: Yes-no question contours in EP (Castelo Branco, Center region), showing truncation (top) and epenthesis (bottom): angeliCAL 'angelic'.

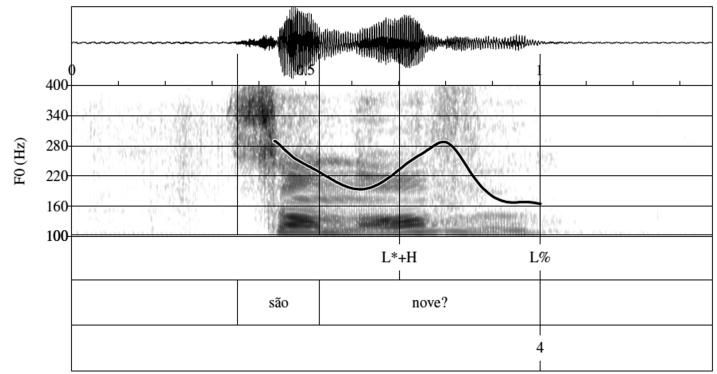

Figure 8: Yes-no question contour in EP (Funchal, Madeira), showing blocking of final schwa deletion in nove 'nine', produced as nov [i]].

Figure 9 shows the patterns of prosodic variation in tunetext accommodation in EP on the basis of the IDW geographical model of analysis. Contrary to BP, where tune adjustments prevail in every region, in EP there is a Northern (tune)-Southern (text) variation pattern. Moreover, in EP adjustments of the text were predominant overall. In summary, $\mathrm{BP}$ and EP were found to differ in the tune-text accommodation strategies used, both in the type of adjustment generally implemented and in the diversity of strategies found across varieties.

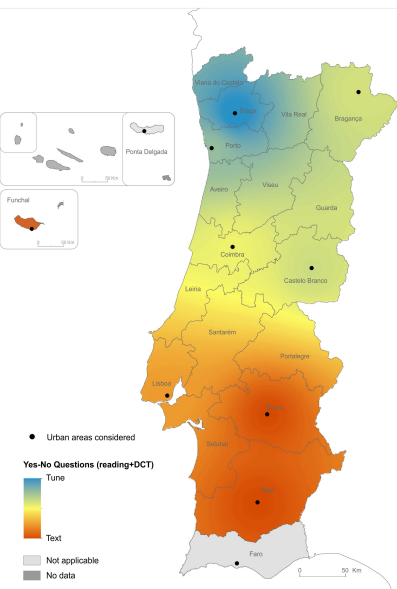

Figure 9: Tune-text accommodation in yes-no questions in EP: mapping prosodic variation using the IDW model.

\section{Conclusions}

In this paper we carried out a systematic study of tune-text accommodation strategies across Portuguese varieties, exploring crucial cases of complex nuclear melodies realized in nuclear words with final stress (and with penult stress and a final schwa vowel, for EP). We show that Brazilian and European Portuguese globally differ with respect to the strategies implemented: in $\mathrm{BP}$, the text is preserved and the melody is changed by means of tonal truncation; in EP, both tune and text adjustments may occur depending on the variety, with a crescendo of text adjustment strategies from the North to the South. Overall, in EP the melody tends to be preserved and the text is changed through various strategies, including schwa epenthesis, vowel split, and blocking of word-final schwa deletion.

Faithfulness to the text or to the melody is thus a relevant dimension of variation both across and within languages, and text changes were found to be crucial means to support tune realization in EP, in line with recent findings for other languages, such as Bari Italian and Tashlhiyt Tamazight [12], [13]. Although much more research is needed, these findings potentially suggest a geo-prosodic effect whereby (some) languages/varieties from Southern Europe and North Africa promote faithfulness to the tune over the text. Future research will also explore whether other features of segmental and/or prosodic phonology correlate with the predominance of faithfulness to the text or to the tune.

\section{Acknowledgements}

This research was supported by grants PTDC/CLELIN/119787/2010 and UID/LIN/00214/2013, FCT, Portugal, and 094912-4, CAPES, Brazil. We thank Pedro Oliveira, Pedro Palma, Nuno Paulino and Bruno Neto for their help with processing of speech files and producing the prosodic variation maps. 


\section{References}

[1] D. R. Ladd, Intonational Phonology. (Cambridge Studies in Linguistics 119). 2nd edition. Cambridge: Cambridge University Press, 2008.

[2] S. Frota and P. Prieto, "Intonation in Romance: systemic similarities and differences", in S. Frota and P. Prieto (eds.) Intonation in Romance. Oxford: Oxford University Press, pp. 392-418, 2015.

[3] E. Grabe, B. Post, F. Nolan and K. Farrar, "Pitch Accent Realization in Four Varieties of British English", Journal of Phonetics, vol. 28, pp. 161-185, 2000.

[4] J. Moraes and M. Colamarco, "Accomodation of Intonational Patterns in Brazilian Portuguese Short Utterances: Compression or Truncation?", in L. Bisol and C. Brescancini (eds.) Contemporary Phonology in Brazil. Cambridge: Cambridge Scholars Publishing, pp. 2-21, 2008

[5] S. Frota and J. Moraes, "Intonation of European and Brazilian Portuguese", in W. L. Wetzels, S. Menuzzi and J. Costa (eds.) The Handbook of Portuguese Linguistics. Wiley, in press.

[6] M. Grice, The Intonation of Interrogation in Palermo Italian: Implications for Intonation Theory. Tübingen: Niemeyer, 1995.

[7] P. Roseano, M. M. Vanrell and P. Prieto, "Intonational phonology of Friulian and its dialects", in S. Frota and P. Prieto (eds.), Intonation in Romance. Oxford: Oxford University Press, pp. 101-139, 2015.

[8] S. Frota, "Nuclear Falls and Rises in European Portuguese: A Phonological Analysis of Declarative and Question Intonation", Probus, vol. 14 (Special issue on intonation in Romance, ed. by J. Ignacio Hualde), pp. 113-146, 2002.

[9] S. Frota, "The Intonational Phonology of European Portuguese", in S.-A. Jun (ed.), Prosodic Typology II. The Phonology of Intonation and Phrasing. Oxford: Oxford University Press, pp. 6-42, 2014.

[10] M. Vigário, The Prosodic Word in European Portuguese. Berlin/New York: Mouton de Gruyter, 2003.

[11] S. Frota, M. Cruz, F. Fernandes-Svartman, G. Collischonn, A. Fonseca, C. Serra, P. Oliveira and M. Vigário, "Intonational variation in Portuguese: European and Brazilian varieties", in S. Frota and P. Prieto (eds.), Intonation in Romance. Oxford: Oxford University Press, pp. 235-283, 2015.

[12] M. Grice, M. Savino, A. Caffo and T. B. Roettger, "The tune drives the text - Schwa in consonant-final loanwords in Italian", Proceedings of the 18th International Congress of Phonetic Sciences. Glasgow, UK: the University of Glasgow, 2015.

[13] M. Grice, R. Ridouane and T. Roettger, "Tonal association in Tashlhiyt Berber: Evidence from polar questions and contrastive statements, Phonology, vol. 32, no. 2, pp. 241-266, 2015.

[14] M. Vigário and S. Frota, "The Intonation of Standard and Northern European Portuguese: A Comparative Intonational Phonology Approach", Journal of Portuguese Linguistics, vol. 2, no. 2, (Special issue on Portuguese Phonology ed. by $\mathrm{L}$. Wetzels), pp. 115-137, 2003.

[15] V. Crespo-Sendra, M. Cruz, J. Silva and S. Frota, "Asking questions across Portuguese varieties", talk given in the 6th International Conference on Tone and Intonation in Europe (TIE), University of Utrecht, Netherlands, September 10-12, 2014.

[16] J. Castelo and S. Frota, "Variação entoacional no Português do Brasil: uma análise fonológica do contorno nuclear em enunciados declarativos e interrogatives", in A. Moreno, F. Silva and J. Veloso, Textos Selecionados do XXX Encontro Nacional da Associação Portuguesa de Linguística, Porto: APL, pp. 113131, 2015. ISBN: 978-989-97440-4-9.

[17] P. Boersma and D. Weenink, Praat - Doing Phonetics by Computer, version 5.3.1, 2012. http://www.praat.org/

[18] S. Frota, P. Oliveira, M. Cruz and M. Vigário, P-ToBI: tools for the transcription of Portuguese prosody. Lisboa: Laboratório de Fonética, CLUL/FLUL, 2015. ISBN: 978-989-95713-9-6. http://labfon.letras.ulisboa.pt/InAPoP/P-ToBI/
[19] G. Cliquet, Geomarketing: Methods and Strategies in Spatial Marketing. GIS - Geographical Information Systems Series. France: Wiley-ISTE, 2006

[20] C. S. Cunha, Entoação regional no português do Brasil. Unpublished $\mathrm{PhD}$ dissertation. Faculdade de Letras, UFRJ, Rio de Janeiro, Brazil, 2000.

[21] M. Paiva Boléo and M. H. S. Silva, "Mapa dos Dialectos e Falares de Portugal Continental", Boletim de Filologia, vol. XX, pp. 85-112, 1961. 